University of Rhode Island

DigitalCommons@URI

Open Access Dissertations

1974

\title{
The Effect of the Conditioned Orienting Response on Learning a Two-Choice Discrimination Task by Mentally Retarded Individuals
}

Edmond S. Zuromski

University of Rhode Island

Follow this and additional works at: https://digitalcommons.uri.edu/oa_diss

\section{Recommended Citation}

Zuromski, Edmond S., "The Effect of the Conditioned Orienting Response on Learning a Two-Choice Discrimination Task by Mentally Retarded Individuals" (1974). Open Access Dissertations. Paper 923. https://digitalcommons.uri.edu/oa_diss/923

This Dissertation is brought to you for free and open access by DigitalCommons@URI. It has been accepted for inclusion in Open Access Dissertations by an authorized administrator of DigitalCommons@URI. For more information, please contact digitalcommons-group@uri.edu. 
THE EFFECT OF THE CONDITIONED ORIENTING RESPONSE ON LEARNING A TWO-CHOICE DISCRIMINATION TASK BY MENTALLY RETARDED INDIVIDUALS

BY

EDMOND S. ZUROMSKI

A DISSERTATION SUBMITTED IN PARTIAL FULFILLMENT OF THE REQUIREMENTS FOR THE DEGREE OF DOCTOR OF PHILOSOPHY

IN

PSYCHOLOGY

UNIVERSITY OF RHODE ISLAND

1974 


\section{ABSTRACT}

The present study attempted to demonstrate that conditioning the skin resistance response in institutionalized retardates would facilitate their learning of a two-choice discrimination task.

Half of the subjects were instrumentally reinforced for the skin resistance response to a white noise stimulus prior to learning a discrimination problem; half were not reinforced in the presence of the white noise stimulus, which subsequently preceded the onset of the discrimination problem.

The findings of the present study were: (1) that no SRR conditioning effect was measured with the parameters and reinforcement used; (2) it was not possible to discern a transfer effect of the SRR conditioning procedure to discrimination learning, probably because no conditioning was obtained; (3) there was no facilitation effect on the number of correct responses when a white noise stimulus immediately preceded the onset of the discrimination task stimu11; and (4) white noise presentation facilitated response latency during the discrimination learning task.

The finding that white noise facilitated response la= tency was related to the retardates' attention deficit. The evidence presented indicated that the retardates' ability 
to attend to a task, and select specific cues, are probably different processes underlying attention.

It was concluded that the facilitated response latency was likely due to the alerting effect of the orienting response elicited by the white noise stimulus. 


\section{ACKNOWLEDGEMENTS}

I am extremely grateful to my mother and father for their love and encouragement during all the days of my life in whatever I have undertaken. They are the greatest!

There is no one word to describe my wife Karen's love, understanding, and professionalism. She was there for the drying of a rain-soaked proposal at one in the morning and assisted as a professional psychologist in evaluating the subjects. Her devotion during this time was without measure and I will always love her for it.

I am especially indebted to Dr. Nelson F. Smith, my major professor. Nelson, in his typical fashion, offered his guidance whenever I asked for it. He had no hours. There are many colleagues and teachers who offered their assistance in many ways supportive of my research. My thanks to Drs. Merenda, Valentino, and Velicer, as well as all who served on my committee at various times.

A special thanks to Dr. John Smith, Superintendent of Ladd School and all the building personnel for their cooperation and assistance when I needed i.t.

Finally, to those whose cooperation made my research possible, the young men and women of Ladd School who volunteered to participate, I offer my heartfelt thanks. We learned from each other. 
TABLE OF CONTENTS

Page

ACKNOWLEDGEMENTS. . . . . . . . . . . . . . . .

ii

TABLE OF CONTENTS . . . . . . . . . . . . . . . . iii

LIST OF TABLES . . . . . . . . . . . . . . . . . iv

LIST OF ILLUSTRATIONS . • • • • • • . • . . . . . v v

CHAPTER

I INTRODUCTION . . . . . . . . . . . 1

II METHOD . . . . . . . . . . . . 18

III RESULTS . . . . . . . . . . . . 28

IV DISCUSSION . . . . . . . . . . . . 46

APPENDICES. . . . . . . . . . . . . . . . . 61

REFERENCES .... . . . . . . . . . . 66 


\section{LIST OF TABLES}

Tables

Page

1. Matching data: means and standard

deviations of mental ages and zero trials. * 24

2. Habituation and conditioning data: mean

number of SRRs/10-trial block . . . . . 31

3. Spearman rho correlations on matching

variables and dependent variables. . . . 35

4. Discrimination data: means and standard

deviations of number of correct responses. - 39

5. Discrimination data: means and standard

deviations of response latencies . . . . 43

6. Means and standard deviations of skin

resistance changes (ohms) . . . . . 50 


\section{LIST OF ILLUSTRATIONS}

Page

1. Mean number of SRRs per ten-trial block. . . 30

2. Discrimination learning: mean number of correct responses per ten-trial block . . . 38

3. Discrimination leaming: mean latency (seconds) per ten-trial block . . . . . . 42

4. Mean change ohms over baseline during habituation (Prials 1 and 20) and conditioning (Trials 1,20 and 50) ..... 49 


\section{INTRODUCTION}

The mentally retarded person is generally described as being a slow learner. The nature of the deficit has been variously attributed to an attention deficit (Zeaman and House, 1963), a short term memory deficit (Ellis, 1963), a response inhibition deficit (Johnson, 1968), and to socioemotional factors (Stevenson and Zigler, 1958; Zigler, 1973), to name a few. The present study addresses itself to the place attention occupies in the learning experiences of retarded persons. More specifically, the retarded as a group have been described as having difficulty in orienting and attending to relevant stimuli when initially confronted with a learning task (Zeaman and House, 1963). Luria (1963) has also reported that the orienting response, a basic component of paying attention, is often absent in the retarded. The purpose of this study was to further explore the importance of the orienting response as it pertains to the retardate's learning deficit. An attempt was made to condition the orienting response to occur more often in retardates in order to facilitate their performance on a simple discrimination task.

Orienting, Defensive, and Adaptive Reactions

When a detectable change occurs in the environment, an organism may respond to it by orienting and attending to 
it (orienting response) by adapting to it without apparently attending to it (adaptive reaction), or by defending against it, e.g. by escape (defensive reaction).

The orienting response is the first reaction of an organism to a stimulus (Sololov, 1963), and it'serves a preparatory function which Heal and Johnson (1970) have described as a focusing of attention or getting ready to respond. Its importance was recognized by Pavlov, and since then attempts have been made to delineate its role in perception (Sokolov, 1963) and learning (e.g. Jeffrey, 1968).

The orienting response (OR) is usually described as a system of physiological and behavioral changes folloring alterations in the environment variously described as novel, surprising, or of altered intensity, color, frequency, uncertainty, etc. (Lynn, 1966).

Some components of human ORs which have been measured are the skin resistance response (SRR), digital blood volume, pulse change (Furedy and Gagnon, 1968), electroencephalographic changes, respiration rate, heart rate, electromyographic charges in the forehead, arm, and leg muscles (Polikanina and Sergeeva, 1967), palmar skin potential (Schnidman, 1970), blood volume in the forehead (Karrer and Clausen, 1967), eye fixation (McCal1 and Kagan, 1969) and cessation of the sucking reflex (Kaye, 1967).

The OR has been distinguished from adaptive and defensive reactions by Lynn (1966) and Horowitz (1969). The 
OR differs from the adaptive reaction in that the or increases sensitivity to stimulation, is nonspecific as to which stimuli elicit it, and it habituates to repetitive stimulation. It readies the organism for action. The adaptive reaction either increases or decreases sensory input to regain equilibrium in specific sensory modalities, or consists of other changes to maintain physiological processes. It does not habituate to repetitive stimulation but continues until a homeostatic condition is regained.

The OR differs from the defensive reaction in that (1) under conditions of prolonged stimulation the oR habituates but the DR intensifies; 2) directionality of response may differ, e.g. heart rate decelerates in the oR but accelerates in the DR; (3) during the of the body may orient toward the source of stimulation, but the DR is characterized as filight away from the stimulus source. OR and Attention

The OR may be distinguished from "paying attention" in that the oR habituates more rapidly than do attending responses except in the case of a conditioned OR. Horowitz (1969) describes the attending response as "a more sustained regard of the organism in relation to a particular stimulus than the oR (p. 101)."

Recent1y, Posner and Boies (197I) divided attention into three theoretical components: alertness, selectivity and processing capacity. They suggested that alertness was 
analogous in function to the OR. It was found to operate independently of the selectivity function on a letter matching task. Reaction times associated with correct matches were inversely related to the interval between the presentation of a warning stimulus, a cross presented just prior to and above the test stimuli, and the onset of a pair of letters to be judged as being the same or different. With the warning stimulus held constant at 500 milliseconds duration, further increases in reaction time were obtained by increasing the interval between letters (the selectivity function). Matching letters, then, was differentially affected by the alertness condition (the warning stimulus) and the selectivity condition. In effect, Posner and Boies (1971) used an exteroceptive stimulus to "increase alertness for processing all external information, to improve selection of particular stimuli, or to do both simultaneously (p. 391)." These findings are relevant here since it was found that alertness was not a selective function, but a general (attentional) process. Once there was alertness (the oR occurred), more information could be selected from the stimulus display (Horowitz" "sustained regard").

OR in the Retardate

Retarded people as a class are typically described as being distractible, slow leamers, and as having a weak OR. Luria (1963) points out that while low or moderately intense stimuli do not elicit ORs from retardates, intense 
stimuli do elicit ORs. Further, Luria (1963) reports that when an OR occurs in a retarded person it habituates rapid$1 y$.

Four measures of autonomic nervous system activity which relate to the oR have been studied in the mentally retarded (Karrer, 1966): (1) resting or base levels; (2) spontaneous fluctuations during rest (e.g. number of spontaneous changes in base level); (3) reactivity to stimulation (e.g. magnitude of response); and(4) rate of habituation to stimulation.

Karrer (1966) summarizes a review of studies of resting level of the autonomic nervous system by stating that "while there seems to be an indication of generally raised resting levels, the only clear-cut finding is the high skin conductance or low skin resistance of defectives (p. 60)." Karrer and Clausen (1964) found that of the autonomic responses they studied (heart rate, heart rate variability, finger volume, systolic blood pressure and skin resistance response), the skin resistance response (SRR) was the most reliable. The resting levels of retardates' skin resistance was one half that of the normals' skin resistance. Karrer (1966) also mentions the possibility of male-female differences in retarded individuals but offered no substantial evidence for this difference.

The raising of skin conductance levels may indicate an alteration in sympathetic nervous activity which could 
affect learning ability. In emergency situations, the sympathetic nervous system prepares the organism to respond to sudden changes in the environment to its best advantage. Abnormality in such activity may be reflected in slower learning ability.

Mental retardates generally display less spontaneous activity than normals when SRR and heart rate are measured. Karrer and Clausen (1964) found that significantly fewer retardates than normals displayed spontaneous fluctuations in SRR during rest. Johnson (1963) measured SRR, heart rate, respiration rate, and electroencephalograph in normal subjects and found that subjects with a large number of spontaneous fluctuations in these measures at rest were more reactive and habituated more slowly than subjects who had fewer spontaneous fluctuations at rest. Mental retardates as a group have less spontaneous activity than normals (Karrer and Clausen, 1964) and, as seen below (e.g. Clausen and Karrer, 1968), are less reactive to stimulation than normals. Karrer (1966) also reviews research which shows that low vigilance levels and longer reaction times are associated with fewer spontaneous fluctuations in skin resistance, a characteristic of the retardates' autonomic functioning. These findings may bear little relation to what the autonomic nervous system does during learning, but it is reasonable to speculate that individials with faster reaction times and who are more vigilant should also be 
better learners, neither factor being displayed by retardates.

That mental retardates are less reactive to stimulation than normals, is indicated by lower amplitude ORs or lack of the OR (Luria, 1963). Clausen and Karrer (1968) studied the effect of repetitive light and sound stimulation on the SRR, heart rate, respiration rate and blood volume in the finger and temple in organic and non-organic retardates and normals matched on IQ and MA. The normals generally had more ORs than either group of retardates, thus indicating a lower reactivity for retardates. Further, the retardates did not display a consistent pattern of OR componentr; e.g. sometimes the SRR was observed, and at other times the blood volume component was observed. One week later on a second test day the SRR and blood volume changes occurred simultaneously but only the SRR measure underwent habituation indicated by fewer subjects having SFRs. The remainder of the measures indicated an increase in responding on the second day by retardates. The finding that normals had fewer such responses on the second day indicated that the stimuli were less novel and thus the OR was not elicited. Of their measures of the OR, there appeared to be less of a criterion problem in measuring the SRR than with most of the other measures. Raskin, Kotsess and Bever (1969) partially confirmed the superiority of the SRR measure in their study comparing the autonomic components of the $\mathrm{OR}$ and the defense 
reaction (DR) in college students. They found SRR and heart rate to be different in magnitude, form, and rate of habituation as a function of white noise intensity. Blood content did not differentiate between the oR and the DR. Grings, Lockhart and Dameron (1962) found differences in SRR magritude between two groups of retardates having mean IQs of 34 and 63. The low IQ group had lower amplitude SRRs than the higher IQ group following a 5.0-second duration stimulus.

Karrer (1966) summarized the available information on the autonomic reactivity of mental retardates as indicating that as a group they tend to be less reactive to simple stimuli (e.g. a tone), especially as indicated by the SRR, and heart rate deceleration. Although no conclusive data were presented, this relationship may not hold for more cumplex stimuli.

Habituation of the oR has been one of the least systematically studied measures of autonomic functioning in the retarded. Vogel (1961) found that although retardates (average group ages 6 and 16 years) were less reactive to loud tone stimuli than normals, they habituated at a rate proportional to that of young (6 year old) nomal children. The retardates, however, habituated faster than older ( 16 year old) normal subjects. Luria (1963) noted that retardates habituated faster to word stimuli than normal subjects, indicating that the complexity of a stimulus is inportant in considering habituation. Clausen and Karrer 
(1968) found that changes in heart rate, respiration rate, head blood volume, and skin resistance, occurred simultaneously in normal subjects but not in retarded subjects. In the retarded subjects, for example, sometimes the SRR occurred, and sometimes heart rate changes occurred, but they seldom occurred simultaneously especially early in the test session. No difference in habituation rates was observed between retardates and normals on the first day but fewer SRRs were observed for the retardates on the second day com pared to their initial data. Pilgrim, Miller and Cobb (1969) did not find a difference in habituation to a light stimulus between normals and mildly retarded subjects. Tizard (1958) on the other hand, found that while normals habituated to a sound stimulus, severely retarded subjects did not. Finally, Fenz and McCabe (1971) found that rate of habituation was somewhat related to stimulus intensity. Retardates habituated faster to a $100 \mathrm{~dB}$ tone than normals but no difference was observed for $35 \mathrm{~dB}$ and $70 \mathrm{~dB}$ tones. Unfortunately, only minimal responding occurred for either group at $35 \mathrm{~dB}$ and little responding was observed for retardates at the $70 \mathrm{~dB}$ intensity, so any conclusion relating stimulus intensity and rate of habituation remains tentative.

In summary, it appears that mentally retarded people have been found to have higher resting levels (higher skin conductance) than normals and that retardates are less re- 
active to stimulation as indicated by autonomic measures. The evidence of the course of SRR habituation in retardates compared to normals is inconsistent, but the SRR appears to be one of the most used and reliable measures of the oR in the mentally retarded.

If the SRR is a component of the OR and is elicited with some difficulty in the retarded who are known to be poor learners, it is possible that part of the learning deficit of the retarded may be attributed to the failure of the OR to occur as it does in "normals."

The Relation of the SRR to Learning and Performance

Lacey and Lacey (1958) found a positive correlation between spontaneous changes in skin resistance and reaction time. Kleinman and Stern (1968), on the other hand, found a negative correlation between spontaneous fluctuations and reaction time. The latter results were the exception rather than the rule since the positive correlation is more commonly found (Boyle, Dykman and Ackerman, 1965; Obrist, HaIIman and Wood, 1964). The subjects used in these studies were college students who presumably had "normal" base levels of resistance, and reacted normally to the stimuli used to elicit the orienting response. The retardate, on the other hand, has fewer spontaneous changes in skin resistance and does not display reliable changes in skin resistance following stimulation. Further, the retardate usually performs more slowly on reaction time tasks than his normal 
counterpart (Baumeister and Kellas, 1968). The relation between the SRR and reaction time suggests that the autonomic functioning, i.e. the SRR, is somehow related to the processes mediating performance on the reaction time task.

Besides having slower reaction times, the retarded have been. shown to have deficits in classical conditioning (e.g. Ross and Ross, 1973) as well as in more complex learning situations (e.g. House and Zeaman, 1958).

In the latter case, while it is possible to obtain single cue, delay conditioning in retardates at longer interstimulus intervals than those used with normal subjects, little if any trace conditioning has been obtained in retarded individuals. Further, differential trace conditioning has not been obtained with retardates. Ross and Ross (1973) mention as one explanation the possibility that retardates do not have an OR to the trace conditioned stimulus. An OR explanation of conditioning requires than an oR be elicited by the conditioned stimulus early in conditioning. Ross and Ross (1973) point out that Grings (1969) obtained differential delay conditioning in retardates, but not differential trace conditioning. This was first interval conditioning with SRR latencies under 5.0 sec., the typical temporal requirement for the SRR component of the OR. The implication here is that the oR occurred to the delay CS and thus delay conditioning was obtained. Perhaps a trace stimulus does not elicit the oR to the extent that 
trace conditioning is possible. In the Ross' laboratory it has also been found that habituation of the heart rate deceleration component of the OR in college students occurs more slowly the stronger the conditioning effect. It appears that better conditioning is obtained in normals when the on does not undergo rapid habituation. Although little habituation data is available for retardates, that which is available tends to indicate that the oR habituates faster compared to normals. This faster habituation could possibly be an underlying factor in the learning deficit exhibited by retardates, even in classical conditioning.

With regard to more complex instrumental learning, Lobb, Moffit and Gamlin (1966) had mentally retarded children learn a discrimination task on the Wisconsin General Test Apparatus and then measured their rate of SRR habituation to novel stimuli. They found that SRR habituation occurred more rapidly for slow learners than for fast learners. Insofar as the SRR indexed a component of attention, the OR, it appeared that retardates display a weak $O R$ and this was reflected in their slower learning. Zeaman (1973) listed further discrimination learning deficiencies in the retarded, and he attributed much of the deficit to the retardates' attention deficit.

Instrumentally Conditioned SRR Related to Task Performance

Changes in skin resistance brought about through instrumental conditioning have been correlated with performance 
on the Seguin formboard (Kimmel, Pendergrass and Kimme1, 1967). Kimmel and his associates noted that others (e.g. Grings, Lockhart and Dameron, 1962) found lower IQ retardates (e.g. 20-45 IQ) to be less reactive to stimulation than higher IQ retardates (e.g. 53-78 IQ). They related these findings to an hypothesis that intelligence is directly related to investigative behavior. If this is true, Kimme1, et al. (1967) suggested "that efforts to modify the strength of oRs instrumentally might be reflected in positive transfer to performance on somewhat more complex, nonverbal intelligence tests (p. 228)." They described the function of the or as being the facilitation of perciption without any restriction as to sensory modality. Razran (1971) points out that the oR is not always correlated with "awareness." It should be kept in mind, then, that ors may serve a preparatory function (e.g. alerting) and that facilitation of performance by the oR should perhaps be thought of as being due to an indirect influence of the OR. Thus, once the "what is it" reflex occurs, other mechanisms (e.g. selection process) may actually account for the facilita tion.

Kimme1, et a1. (1967) compared the performance of retarded and normal children after instrumentally conditioning the SRR to remain above baseline resistance. Measures of formboard performance were taken two nonths prior to, and immediately following, the conditioning session. Drring conditioning, al1 the subjects were first presented 15, 
nonreinforced presentations of geometric shapes on a screen. These data revealed that retardates habituated more quickly than normal children. The retardates ORs (SRR) were smaller in amplitude (change in baseline) but not significantly different from the normals' amplitude. The subjects were next divided so that half the retardates and half the normals received a reinforcement (a piece of candy dropped into a cup) if the SRR occurred during the last two seconds of the stimulus duration (time not reported). The remaining subjects were reinforced for not responding during the last two seconds of stimulus duration. The intertrial interval varied from 50 to 60 seconds. Each time the criterion was met for either group, a voice said "good" over the intercom and an assistant sitting next to the subject dropped a piece of candy into a cup.

During acquisition, the overall retardate-normal difference was significant but with the normals reinforced for not responding having the greatest $10 \mathrm{~g}$ conductance response magnitude. None of the remaining groups appeared to habituate as had occurred when the initial 15 stimuli were presented without reinforcement. It appears, then, that regardless of reinforcement contingency, the presence of reinforcement prolonged the habituation of the OR.

of interest here was the finding that the reinforcement contingency in the retardates was related to improved performance on the Seguin formboard given immediately fol- 
lowing conditioning. Seven of the normal subjects reinforced for SRRs during conditioning showed improved performance; six of the normals reinforced for not giving SRRs improved and four performed more poorly than before. A normal control group was run separately from the other groups; these subjects were simply tested on the formboard at two different times without experiencing any conditioning at all. Four out of ten control subjects did better than before while the remaining subjects did not do as well as the first time.

Most interesting were the results obtained for the retardates. Eleven of the twelve retardates contingently reinforced for the SRR improved on the task while of the "noncontingently" reinforced subjects, six of the eleven improved. It appears that instrumental reinforcement of the orienting response had some transfer to instrumental performance in spite of an apparent lack of conditioning effect between the retarded groups.

Thus far, the results of Kimmel, et aㅡ. (1967) have not been replicated nor has any other attempt been made to study the effect of conditioned ORS (SRR) on performance of any other task.

The purpose of the present study was to investigate the feasibility of conditioning the on to a stimulus (white noise) and the effectiveness of using that stimulus as part of another learning task. 
This study differs from and expands upon the Kimme1, et al. study (1967) in several ways. Unlike the Kimmel, et al. study, a two choice discrimination problem was used and pennies were used as reinforcers instead of candy. Further, the subjects in the present study were institutionalized mentally retarded ranging in chronological age from 13 to 32 years. In order to have greater control of the SRR with respect to experimental condition (i.e. presence or absence of conditioned SRR), a second independent variable was added to the design. A white noise stimulus was first used as a part of a procedure in which the SRR was instrumentally reinforced with pennies. The white noise was then either presented or not presented immediately before the onset of two stimuli to be discriminated. Thus, more confidence in the presence or absence of a conditioned oR was possible. The present study tested the hypothesis that learning a fairly difficult task by retardates would be significantly facilitated by the occurrence of an external stimulus previously presented contiguously with a reinforced orienting response.

The performance of four groups of retardates on a two choice discrimination task was then compared. Half of the subjects had previously been instrumentally reinforced for the SRR to a white noise stimulus and haIf had not been reinforced for the SRR to a white noise stimulus. 
The performance of the following four groups on the discrimination task was compared: Group CWN, contingent 1 y reinforced for the SRR during conditioning and given white noise as part of the discrimination task sequence; Group CNWN, contingently reinforced for SRR during conditioning but no white noise during discrimination learning; Group NCWN, random reinforcement during SRR conditioning and white noise during discrimination learning; and Group NCNWN, which had random reinforcement during the SRR conditioning and no white noise during the discrimination task.

The following ranking of groups from best to poorest discrimination performance was predicted: (1) CWN (2) CNWN (3) NCWN (4) NCNWN, With regard to the ranking, Group CWN would confirm the hypothesis stated above. Group CNWN was somewhat similar to the retarded experimental group of Kimmel, et a1. (1967) and if instrumental reinforcement of the SRR was effective they should have performed better on the learning task than subjects who were not reinforced for the SRR. It was predicted that Group NCWN would perform better than Group NCNWN because of the possibility that the white noise itself would elicit the of and thus facilitate performance on the discrimination task. 


\section{METHOD}

\section{Subjects}

The subjects were 64 residents at the Dr. Joseph Ladd School, a state institution for the retarded in North Kingstown, Rhode Island. Thirty-six males ranging in age from 13 to 32 years, and 28 females ranging in age from 13 to 30 years participated. Their degrees of retardation ranged from profound to mild with most subjects falling in the severe (25-39 IQ) to moderate (40-54 IQ) range. The mean IQ was 26 and the range of IQs was 10-62, with a standard deviation of 10.5. These subjects constituted the majority of testable residents available for this project. Residents having known organic involvement were excluded from the study.

\section{Apparatus}

The main components of the apparatus used are described below.

The skin resistance was measured and recorded using a Narco-Bio Systems Physiograph (DMP 4A, Rectilinear). Lead finger electrodes and a silver plated arm plate electrode, in conjunction with the Physiograph GSR coupler, were used in skin resistance recording.

The white noise stimulus of the desired duration was provided by a Grason Stadler (901B) White Noise Generator 
in conjunction with an interval timer.

A Lehigh Valley 12 choice response panel formed the basis of the discrimination task. Twelve green, yellow, red and blue lighted buttons approximately $1.6 \mathrm{~cm}$. square were arranged in four rows and three columns, and the colors were scrambled on the panel. A Lehigh Valley panel. mounted penny dispenser provided the reinforcements. Programming was accomplished using standard electromechanical programming equipment.

Procedure

The experiment was run in a large storage room, dimly illuminated by two 25 watt red light bulbs to minimize distraction. The ambient room temperature ranged from $68^{\circ}$ to $72^{\circ} \mathrm{F}$. The white noise stimulus which was presented through headphones had an intensity of $71.5 \mathrm{~dB}$ SPL, and was of 3.0 sec. duration during measurement of reactivity and of 0.5 sec. duration during the conditioning and learning phases of the study.

The skin resistance recording was done in the capacitive mode of the Physiograph. Alcohol was used to clean the subjects' fingers prior to placement of the electrodes. Lead electrodes were attached with tape to the index and middle fingers of each subject's non-preferred hand. These fingers were then taped together to minimize movement. The silver plated indifferent electrode was attached to the inside of the opposite forearm just above the wrist. The 
preferred hand was determined by asking the subjects which hand they used in eating.

For preliminary recording purposes, the subjects sat in a chaise lounge chair, facing a blank wall. The chair supported both head and legs, thus reducing the chance of unwanted movements. The experimenter stood close behind and to the right of the subjects, allowing observation for movement of both hands and feet.

While the discrimination response panel had three columins and four rows of red, green, yellow and blue square pushbuttons that could be illuminated, the system was wired so that only two stimuli lit up on a given trial. The color green was correct on every trial and paired with a red, yellow or blue button. The spatial position of the stimuli also varied from trial to trial. The task was arranged so that either correct or incorrect responses terminated the stimuli and activated a tape timer which controlled the intertrial interval. A variable-40 sec, intertrial interval was used in both the conditioning and discrimination learning phases of the study.

Pennies were used as reinforcers for both criterion skin resistance responses and correct responses on the learning task. The reinforcement dispenser was located directly below the response panel. A $45 \mathrm{msec}$. red-light flash on the dispenser panel accompanied each reinforcement. During conditioning, the relay rack containing the response 
panel and dispenser was placed by the subject's right side in full view. During the learning phase the footrest was removed from the chaise lounge and the response panel and penny dispenser were placed directly in front of the subject.

Matching of Groups

The four groups were matched on the basis of mental age (MA) and on the number of trials on which no SRR was observed (zero trials) when a series of 20 white noise stimu1.i was presented to each subject. The subjects were matched on MA to control for possible initial differences in learning ability, and on "zero trials" to control for initial reactivity on the skin resistance measure.

Approximately six to eight weeks prior to their participation, the subjects were tested using the columbia Scale of Mental Maturities (CSMM) (1953) to obtain their mental ages. The test was administered by the experimenter and a certified school psychologist. The CSMM was used because it did not require overt verbal responses; because it required a pointing response similar to the learning task; because it required discriminations to be made on both color and position dimensions, both important to the learning task; and because of its ease of administration.

Three to four weeks prior to the main experiment, the subjects were brought to the experimental room to accustom them to the recording apparatus and to obtain a measure of 
SRR habituation, to be used as a matching variable. At this time the electrodes were attached to the subjects' index and middle fingers and a 10 min. adaptation period was given. The subjects were asked to wear the headphones. After 10 min., a series of twenty $71.5 \mathrm{~dB}$ SPL, 3.0 sec., duration white noise presentations were delivered through the headphones and the SRR to each stimulus was measured.

For matching, the subjects were first ranked on each measure. They were then assigned, according to mental age in a counterbalanced order, to either a contingent reinforcement condition (c) or noncontingent reinforcement condition (NC). Next, the subjects frrm each of these groupings were randomly assigned either to the WN or NWN condition on the basis of the number of zero trials in habituation.

The following four groups were formed: Group CWN, contingent reinforcement in white noise/SRR conditioning and white noise preceding the learning task; Group CNWN, contingent reinforcement in white noise/SRR conditioning, but no white noise preceding the learning task; Group NCWN, noncontingent reinforcement in white noise/SRR conditioning and white noise preceding the learning task; and Group NCNWN, noncontingent reinforcement in white noise/SRR conditioning and no white noise preceding the learning task.

It should be noted that no hearing test was given to the subjects prior to rumning them in the experiment. Conceivably, reactivity would be limited in subjects with a 
hearing impairment, i.e. the effective intensity of the white noise stimulus would be reduced, then also the SRR. It was felt that since the eroups were matched on SRR reactivity however, that any efiect of hearing differences on the outcome of the experiment would be minimal.

Table 1 shows the mean number of zeros per subject, mean mental age, and respective standard deviations for each group. $F_{\max }$ tests were made separately on both the zero and the mental age data to determine the accuracy of matching. The result for the zero matching variable was $F_{\max }=1.24$ for $15 \mathrm{df}$, which is not significant, The $F_{\max }$ for mental age was 1.43 for $15 \mathrm{df}$, which is also not significant. Since neither of these $F_{\max }$ values were significant, it was assumed that the within groups variances on either matching variable did not differ between groups and the subjects did not differ with respect to zeros or mental age.

\section{SRR Conditioning}

Each subject had 50 conditioning trials. The experimenter explained to the subjects that another session of a similar nature to what had been done last time during habituation would be done again. The following instructions were given to the subjects prior to conditioning:

"I am going to give you pennies for just sitting still and looking straight at the light. The pennies will come out here (demonstration) and the light will flash when they come out. Remember to sit still and see how many pennies you can get so you can spend them at the canteen." 
TABLE 1

Matching Data

Means and Standard Deviations of

Mental Ages and Zero Trials

\begin{tabular}{|c|c|c|c|c|}
\hline \multirow{2}{*}{ Group } & \multicolumn{2}{|c|}{ Zero Trials } & \multicolumn{2}{|c|}{ Mental Age } \\
\cline { 2 - 5 } & $\overline{\mathrm{X}}$ & $\mathrm{SD}$ & $\overline{\mathrm{X}}$ & $\mathrm{SD}$ \\
\hline CWN & 6.94 & 4.04 & 66.31 & 23.31 \\
\hline CNWN & 6.00 & 5.01 & 65.00 & 23.11 \\
\hline NCWN & 6.19 & 4.83 & 65.31 & 20.90 \\
\hline NCNWN & 6.13 & 4.03 & 66.50 & 23.09 \\
\hline
\end{tabular}


The operation of the penny dispenser was then demonstrated for each subject and the subjects were asked to face the feeder and watch the red light flash, indicating that they earned a penny.

During conditioning, 50 white noise stimuli were presented with a variable 40 sec. intertrial interval. Responses that occurred within a $1.5-5.0$ sec. scoring window measured from the white noise onset, were considered to be criterion responses as 1ong as they reached $0.5 \mathrm{~mm}$ on the $10 \mathrm{mv} / \mathrm{cm}$ scale of the Physiograph (50 ohms) and if no movement was simultaneously observed. The white noise used in conditioning was approximately $71.5 \mathrm{~dB}$ SPL and had a 0.5 sec. duration. The stimulus duration was changed so that the stimulus would be somewhat different from the one used in the habituation series.

In the contingent reinforcement condition, only criterion responses were reinforced. The penny was given approximately when the response reached its peak amplitude. An effort was made not to reinforce the subjects of either contingency condition while they were moving. The subjects who were noncontingently reinforced received the same number of pennies as the contingently reinforced subjects they were paired with. Further, noncontingently reinforced subjects were reinforced on random trials, regardless of whether a response occurred in the scoring window, and after 5.0 sec. of the trial had elapsed. This meant that the re- 
inforcement was never given contingent on tire SRR. If there was a response on a prescribed trial, no reinforcement was given until the skin resistance reached baseline level. Discrimination Learning

All of the subjects had the conditioning and discrimination learning phases in a 2 hour session on a single day. After the 50 conditioning trials, the overhead lights were turned on for approximately five minutes. During this time, the electrodes were removed and the subject was allowed to relax, collect the pennies earned during conditioning, and put them into a plastic bag provided by the experimenter. At this time the footrest was removed from the chair and the response panel was illuminated. The response panel was now placed directly in front of the subjects and the room lights were turned off. $\$ 11$ subjects wore the headphones regardless of condition.

The following instructions were given to each sub.ject:

"We are going to play a game now. If you press the right (correct) color with your finger you will get a penry just as before. If you press the wrong color you will not get a penny. Wait for the lights to come on and touch the colors. See how many pennies you can get."

Immediately following instructions, the subjects were allowed to press a button for the first trial. The discrimination task was fully automated with a variable 40 sec. intertrial interval. The sequence of experimental events in discrimination learning was: (1) one-half second duration white noise (when specified); (2) two test stimuli 
appear on the test panel; (3) offset of the panel initiated by a response with correct responses reinforced, and(4) begin VI 40 intertrial interval. 


\section{RESULTS}

The purpose of the present study was to determine if conditioning an orienting response in retardates, measured by the SRR, would facilitate their subsequent performance on a two choice color discrimination task. First, an attempt was made to instrumentally condition the SRR elicited by a white noise stimulus. Second, the effect of the or conditioning on the learning of a simple discrimination task was to be assessed.

\section{Habituation and Conditioning}

The mean number and standard deviation of SRRs per trial block during both the initial habituation series and conditioning are presented in Figure 1 and Table 2.

A series of twenty, 3.0 sec. duration stimuli was presented through headphones during the habituation phase of the experiment. These data were then used to match the groups (see Appendix A, Table 1). The habituation curves presented in Figure 1 (left panel) represent group data combined after the habituation phase and matching were accomplished.

After 20 stimulus presentations, many responses were still recorded for each group. The rate of habituation indicated by the steepness of the curves does not appear to differ between groups. 
Fig. 1: Mean number of SRRs per ten trial block. 


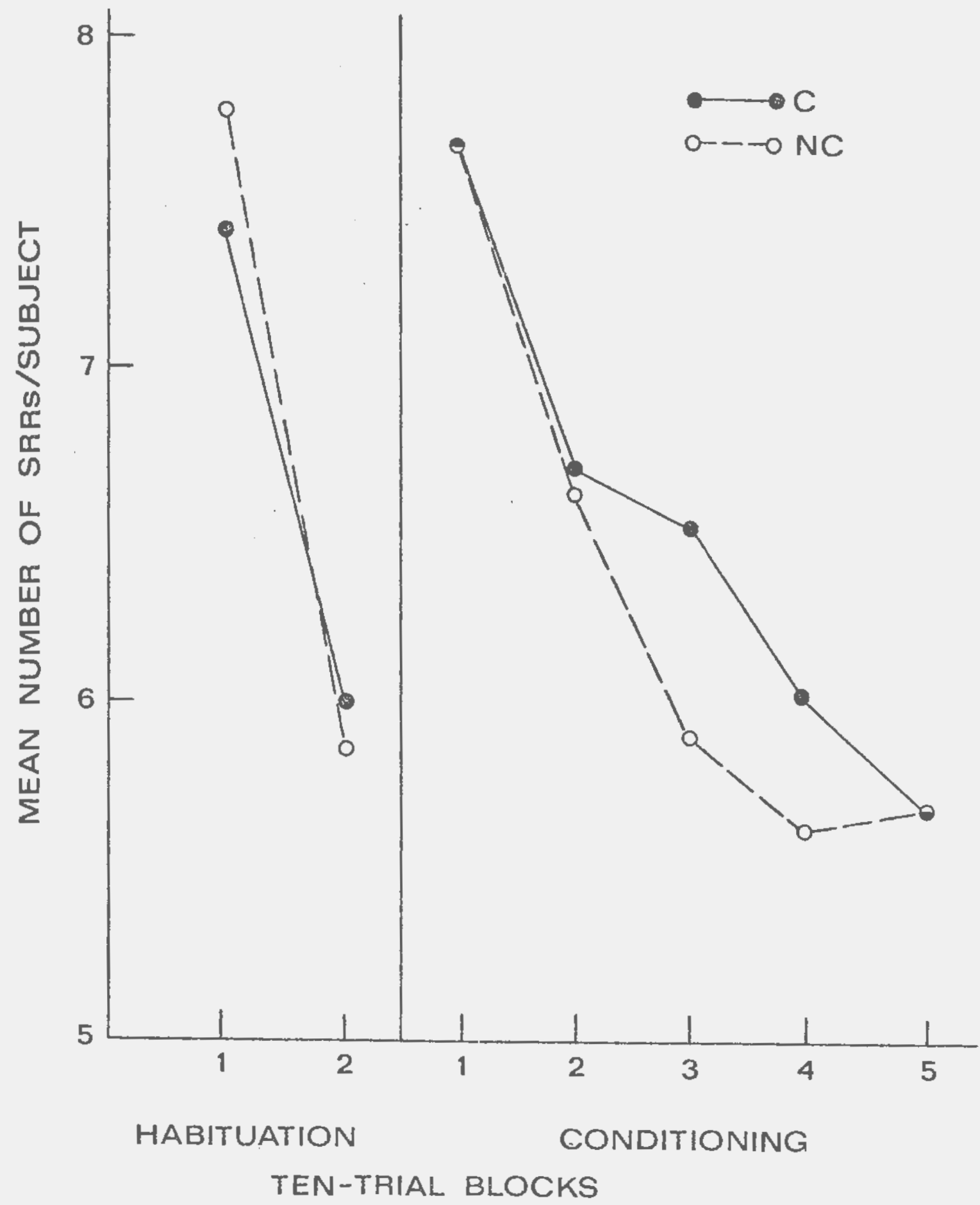




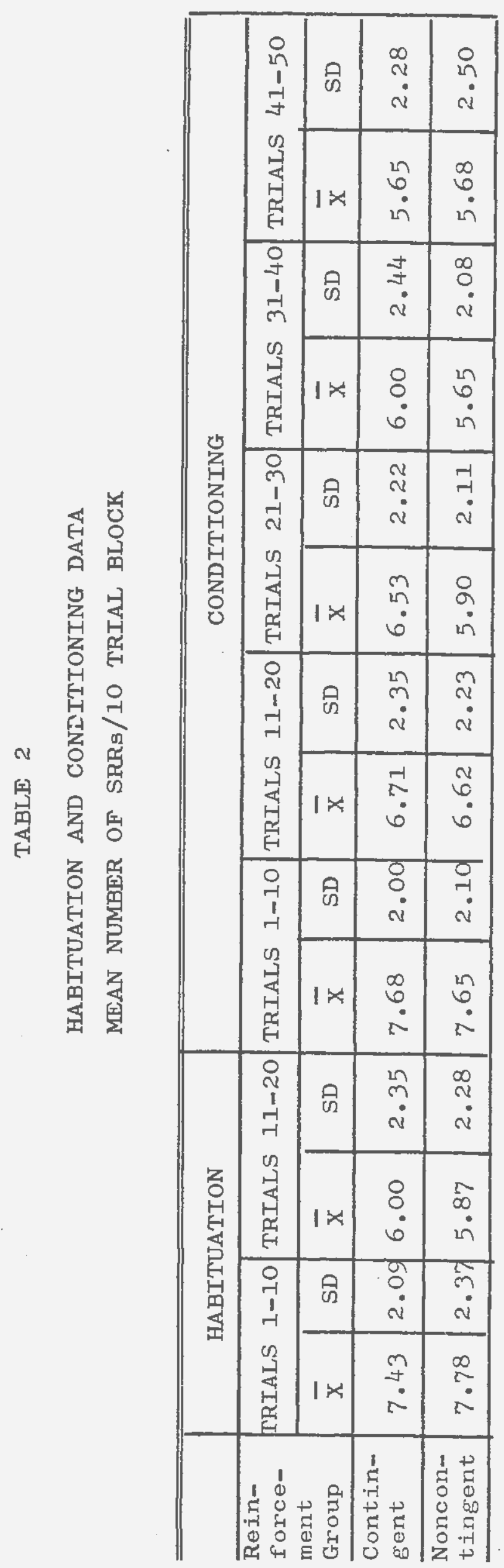


Three to four weeks after the habituation series was run, the subjects were again presented the white noise stimulus during conditioning (right panel of Figure 1). This time the stimulus duration was $0.5 \mathrm{sec}$, the intensity remained the same as before.

At the outset of conditioning, the subjects made approximately the same number of responses as they did during the first ten trials of the habituation series. Further, the rate of habituation (at least for the first 20 trials) did not appear to differ appreciably between the habituation and the conditioning phases.

During conditioning, the subjects were not reinforced for SRRs recorded when they moved their hands or feet. The contingently reinforced group (c) and the noncontingently reinforced group (NC) did not differ significantly on the number of skin resistance responses (ANOVA, Fixed Effect Mode1, 2 Factor) (Groups and Trials) - One Repeated Measure, (Trials), F< 1.0) (see Appendix B, Table 1 for ANOVA source table). The $\mathrm{C}$ group had a total of only slightly more (1043 vs. 1009) responses than the NC group. Both the C and the NC groups exhibited habituation or a decrease in responding to the white noise stimulus over trials (ANOVA, $\mathrm{F}=17.7, \mathrm{df}=4 / 248, \mathrm{p}<.001$ ). It appears in Figure 1 (right panel) that the $C$ group habituated more slowly than the NC group, but the Trials $X$ Conditioning interaction was not statistically significant $(F<1,0)$. 
To summarize the SRR data, habituation occurred during the habituation trials but full recovery of the SRR occurred by the time the subjects encountered the white noise stimulus for the second time at the outset of the conditioning phase. Although complete habituation of the SRR was not evident, that is, all the subjects did not cease to respond to the white noise completely, the number of SRRs decreased significantly over both habituation and conditioning trials for both the $\mathrm{C}$ and the NC groups. The groups did not differ significantly either on the total number of SRRs or on the rate of habituation. Instrumental reinforcement had no significant effect on the number of SRRs, or on the rate of SRR habituation between groups. It is not known if perhaps some other component of the OR was affected by reinforcement since only the SRR was measured. Discrimination Learning

In the second phase of the study, the subjects had to learn a simple discrimination task with either white noise present or absent just prior to the onset of the task stimu1i. This design was intended to be used to study the effect of transfer of a possible white noise-SRR conditioning effect to the learning of the discrimination task. Both the number of correct responses and response latencies were recorded as dependent variables on the discrimination task. The discrimination phase was run without having obtained SRR conditioning for two reasons. First, because the design 
of the experiment required that the subject learn the discrimination task immediately follcwing conditioning, in a single session so the lack of measurable conditioning was not yet known. The possibility also existed that the or was indeed conditioned but not reflected in the measure used and that the effect would show in the discrimination task.

The appropriate statistical analysis for the discrimination problem data was the analysis of covariance since measures on two covariates, mental age and SRR reactivity measured by zero trials, were obtained prior to the experiment for purposes of matching groups. With the present data, however, the requirement for equal regression siopes was violated. The correlations between each dependent variable and the covariates are presented in Table 3. Ideally, there should be no difference between the group correlations. This would indicate that equal amounts of variance contributions were made by the covariates in each cell. The correlations between mental age and number of correct responses, and latency, were statistically significant only for groups CWN, CNWN and NCNWN. Skin resistance reactivity also correlated significantly with the number of correct responses for groups CWN and NCNWN. The only significant correlation between SRR reactivity and latency was for group NCNWN. The reason for these significant correlations is not evident. There does appear to be a pattern, however, with significant correlations between both covariates and the 
TABLE 3

PEARSON PRODUCT-MOMENT CORRELATIONS ON MATCHING VARIABLES AND DEPENDENT VARIABLES

A. Mental Age

\begin{tabular}{|l|c|c|}
\hline \hline Group & Correct Responses & Response Latency \\
\hline CWN & $.72 * *$ & $-.58 *$ \\
\hline NCWN & .28 & -.25 \\
\hline CNWN & $.52^{*}$ & -.44 \\
\hline NCNWN & $.64 * *$ & $-.57^{*}$ \\
\hline
\end{tabular}

* $\quad \mathrm{P}<.05$

* $\quad \mathrm{P}<.01$

B. SRR Reactivity

\begin{tabular}{|c|c|c|}
\hline Group & Correct Resporses & Response Latency \\
\hline CWN & $.52^{*}$ & -.14 \\
\hline NCWN & .41 & -.32 \\
\hline CNWN & -.01 & -.13 \\
\hline NCNWN & $.54 *$ & $-.51 *$ \\
\hline
\end{tabular}

* $\quad P<.05$

$* * \quad \mathrm{P}<.01$ 
number of correct responses and between mental age and 1 atency for groups CWN and NTCNWN.

Because a crucial assumption of the covariance analysis was violated, the analysis of variance was used to analyze the data. In all cases a Fixed Effect Model was followed in the data analysis. The correct response and latency data were both analyzed with a three factor (conditioning, white noise, trials) - one repeated measure (trials) analysis (Appendices C and D, Table 1). The mean number and standard deviation of correct responses per 10 trial blocks are presented in Figure 2 and Table 4.

Although the number of correct responses increases significantly over trials (ANovA, $\mathrm{F}=18.5, \mathrm{df}=4 / 240, \mathrm{p}<.001$ ) (see Appendix C, Table 1 for source table), the groups did not differ on the number of correct responses made. Since no conditioning of the SRR, a measure of the oR, occurred, no difference due to conditioning would be expected. The group having contingent reinforcement during conditioning and which received the white noise just prior to the onset of the learning task stimuli (Group $C W N$ ) appeared to have reached a superior level of responding in the second trial block but this difference was not statistically significant. The other groups obviously did not differ from one another throughout the course of learning trials.

The presentation of a white noise stimulus had no significant effect $(F<1)$ on the number of correct responses 
Fig. 2: Discrimination learning: Mean number of correct responses per ten-trial block. 


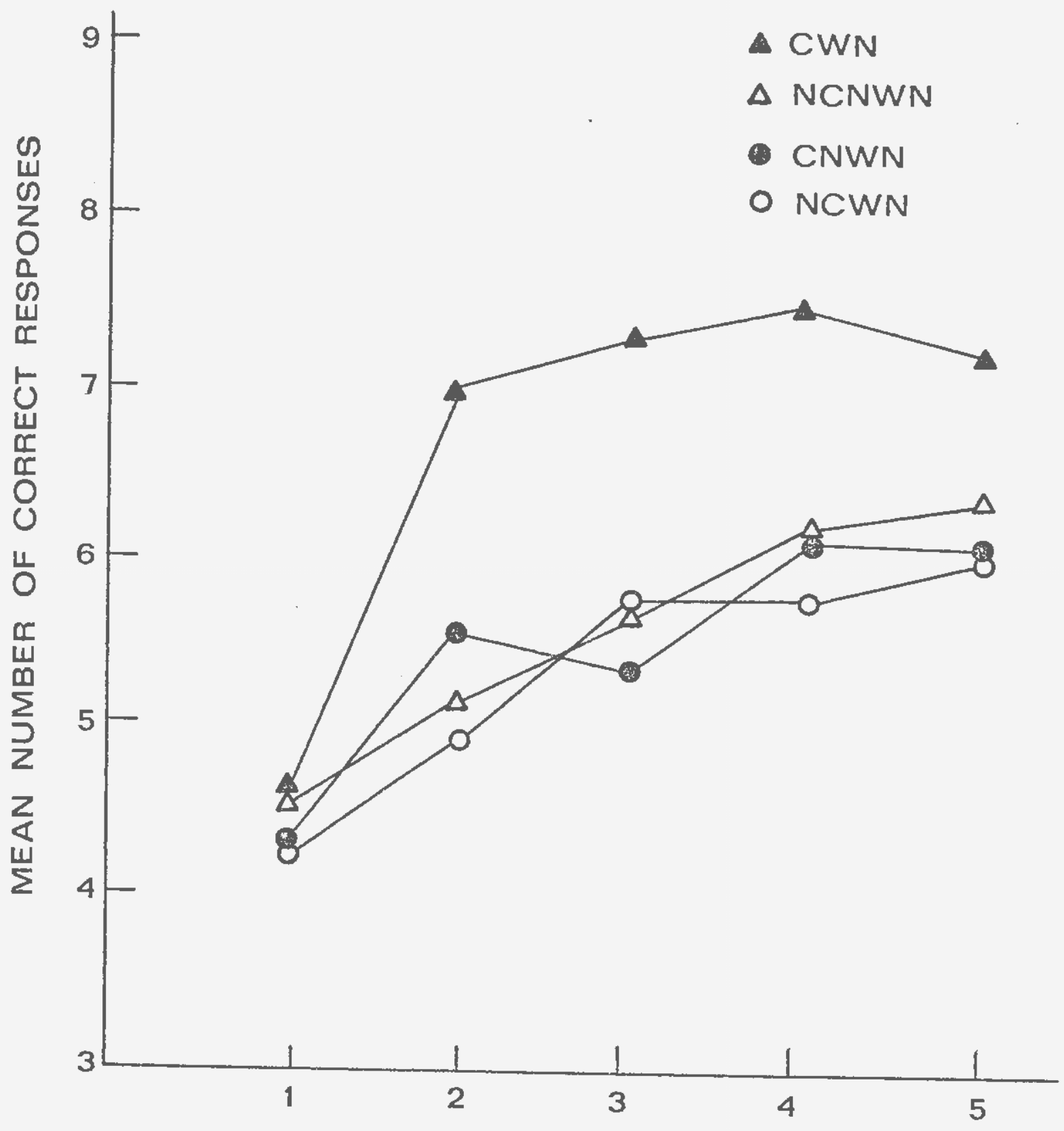

TEN-TRIAL BLOCKS 


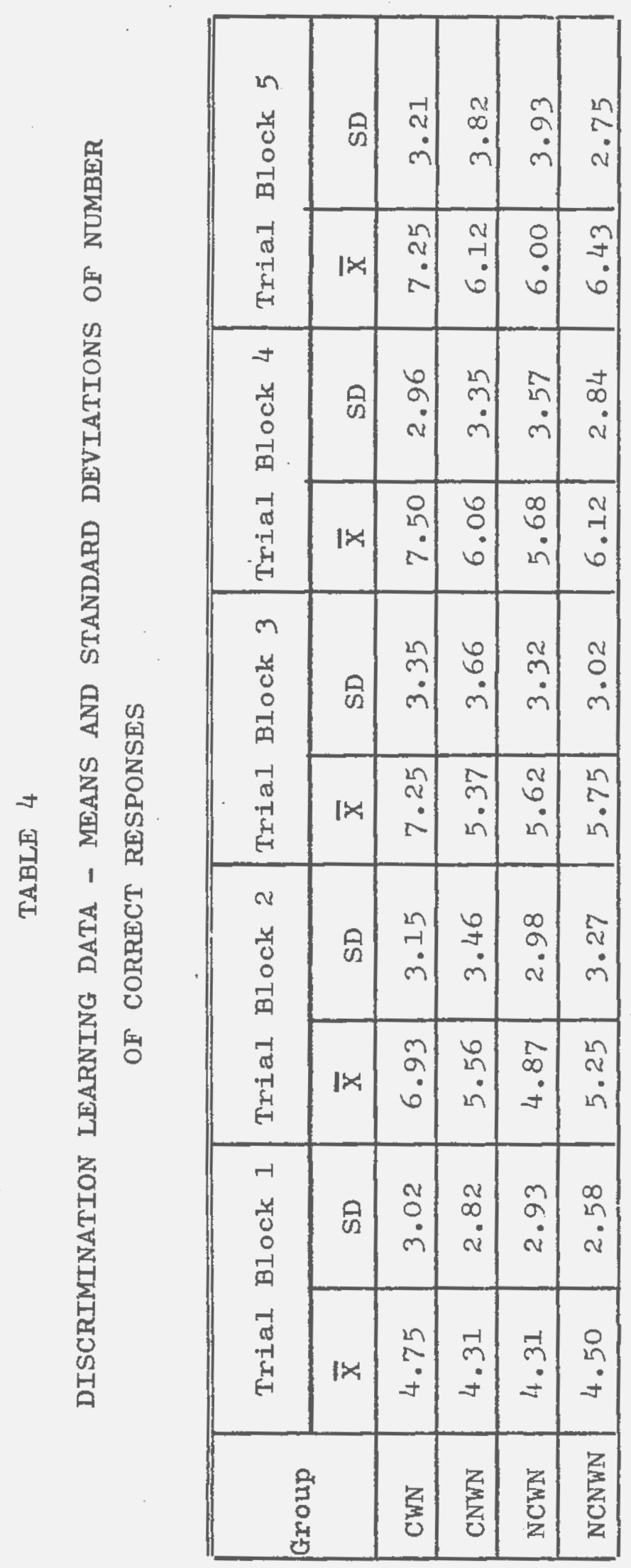


(Appendix C, Table 1). The three way interaction, $\mathrm{T} X \mathrm{C} X \mathrm{~W}$, (Appendix C, Table 1) was significant ( $F=13.50, \mathrm{df}=4 / 240$, $\mathrm{p}<.001$ ) but its interpretation is made difficult in the absence of a significant conditioning effect. Perhaps an OR did occur during the discrimination learning but if an OR was elicited, it had no significant effect on correctness of responding.

In summary, it is evident that learning was demonstrated by all groups (indicated by the significant Trials effect). Since no significant SRR conditioning effect was measured, it was not possible to determine the effect of SRR conditioning on the learning of tre discrimination task.

Although the conclusions to be drawn from the number of correct response data are limited, this is less the case when performance on the discrimination task was measured by response latency. Each subject's latency of responding was obtained during the learning phase. After the intertrial interval the stimulus panel would light and remain lit until the subject made either a correct or incorrect response. Latency was measured as the time from stimulus onset to when the response was made.

The mean latency data are presented in Figure 3 and Table 5. For purposes of presentation and analysis, Trials 1-5 and Trials 46-50 are not shown. Since the first trial for each subject was given immediately following the instructions while the task stimuli were on, aIl the subjects had 
41

Fig. 3: Discrimination learning: Mean latency (seconds) per ten-trial block. 


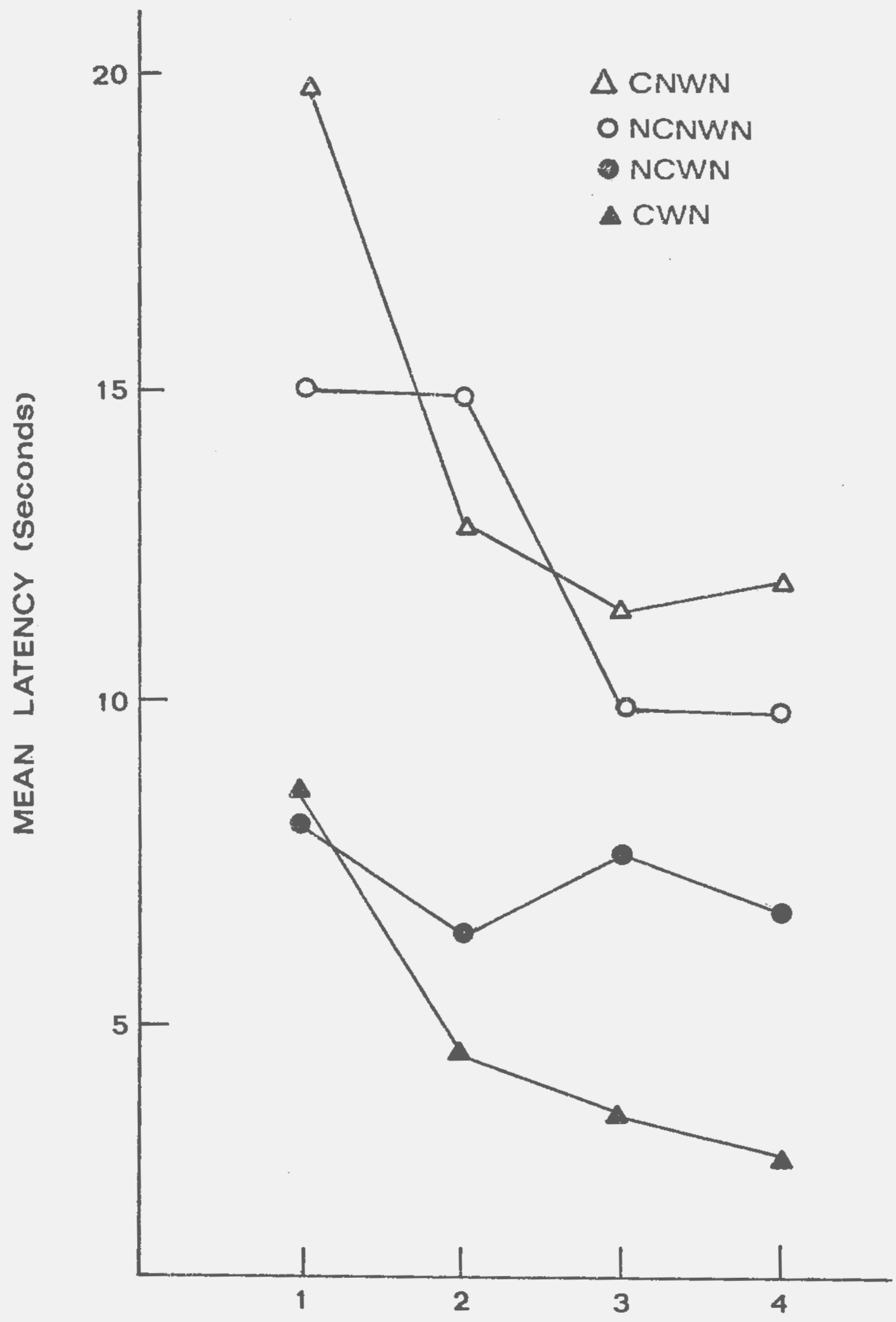

TEN-TRIAL BLOCKS 


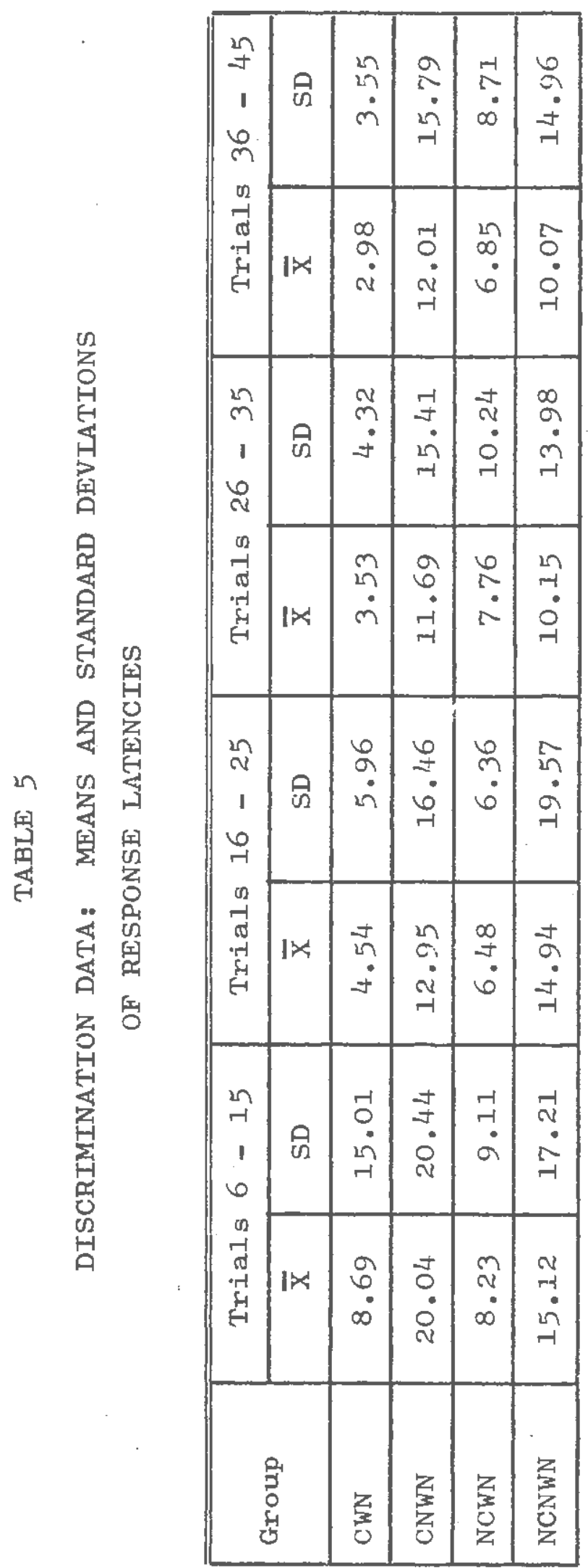


latencies greater than 60 sec. on trial 1. Also, not all the subjects understood the instructions, that is, did not push the buttons immediately, so the latency data were highly variable for the first five trials. Since the data were blocked by tens, the first and last five trials were excluded from the analysis of variance.

Despite the variability seen in Table 5, the analysis of variance was used to analyze the latency data. Confidence may be placed in this test even though the underlying assumption of homogeneity of variance is not met if certain criteria are satisfied. Specifically, if the $\mathrm{n}^{\prime} \mathrm{s}$ are equal (Boneau, 1960) and if the shapes of the group distributions are similar as demonstrated by the Norton study presented in Lindquist (1953), there should be little difference between the F's obtained on the present data, and F's obtained if al1 the assumptions of the ANOVA were met. The $n^{1} s$ were equal in this study and the distributions for each of the groups were positively skewed and highly similar.

As seen in Figure 3, all groups performed faster as the task progressed (ANOVA, Trials; $F=7.60, \mathrm{df}=3 / 180$, p <.001) (see Appendix D, Table 1 for source table). The two groups (CWN and NCWN) having the white noise immediately preceding the task performed with the shortest latencies (White Noise, $F=5.71, \mathrm{df}=1 / 60, \mathrm{p}<.025$ ). A1though it appears that the subjects who were contingently reinforced during conditioning and who had the white noise as part of 
the task (Group CWN) made the most correct responses (see Figure 2), and also responded with the shortest latencies (see Figure 3), these differences were not statistical1y significant. The subjects who received the white noise on the learning task, regardless of reinforcement contingency, responded faster than subjects who did not receive the white noise. Since no SRR conditioning was measured in the first phase of the study, no conclusion can be made as to the effectiveness or ineffectiveness of conditioning the oR in its effect on decreasing the subjects' latencies on the discrimination learning task.

Only one of the original predictions made at the outset of this study was partially supported by the data, that is, that white noise would produce better performance. The important factor in facilitating speed of response seems to be the presence of the white noise stimulus preceding the onset of the task stimuli. Irrespective of prior conditioning, the groups having the white noise preceding the learning task performed faster and this difference was maintained throughout the four trial blocks. The white noise did not, however, affect the correctness of responding. 


\section{DISCUSSION}

The present study attempted to demonstrate that conditioning the skin resistance response in retardates would facilitate their learning a two-choice discrimination task.

The findings of the present study were: (1) that no SRR conditioning effect was measured with the parameters and reinforcement used; (2) it was not possible to discern a transfer effect of the SRR conditioning procedure to discrimination learning, probably because no conditioning was obtained; (3) there was no facilitating effect on the number of correct responses when a white noise stimulus immediately preceded the onset of the discrimination task stimuli; and (4) white noise presentation facilitated response latency during the discrimination learning task.

According to Sokolov (1963), orienting responses which have become habituated to a stimulus should be smaller in amplitude and habituate more quickly in subsequent encounters with that stimulus. Neither of these observations can be made in the present data with number of SRRs as the dependent variable. If the first 20 trials of the habituation and the conditioning phases are compared (see Figure 1, p. 30), there appears to be little difference either in the number of responses or in the rate of habituation. Recovery of the SRR occurred between the second trial block of habituation and the first trial block of conditioning. 
When the actual mean changes in skin resistance are presented (see Figure 4, Table 6), there does not appear to be any difference in the rate of habituation between the two phases of the experiment, but the subjects had smaller SRRs on Trial 1 of the conditioning phase than on Trial 1 of the habituation phase (Wilcoxen Sign Test, $Z=4.55, \mathrm{p}<.001$ ). This lower reactivity reflects the expected result of previous habituation, that is, that subjects are less reactive to a stimulus after having experienced it once before.

Although no normal-retardate comparison can be made in the present data, it appears that the habituation process functioned much as would be expected in a normal population following white noise stimulation. This suggests that the initial responsiveness to stimulation may be the more important variable in the retardate's attention deficit. Once the oR is elicited, habituation appears to occur, much the same in retardates as it does in normals. In line with this suggestion, Pilgrim, et al. (1969) reported finding no difference in SRR habituation between normals and retardates. An unexpected finding in the conditioning phase was the lack of evidence of SRR conditioning. There are several possible reasons for not finding SRR conditioning. For example, it is possible that the SRR measured was not a sensitive enough indicator of a conditioned oR. Since no concomitant measures of the oR were taken it is not possible to know whether some other measure of the oR might have shown 
Fig. 4: Mean change ohms over baseline during habitration (Trials 1 and 20) and conditioning (Trials 1, 20 and 50). 
MEAN CHANGE OHMS OVER BASELINE

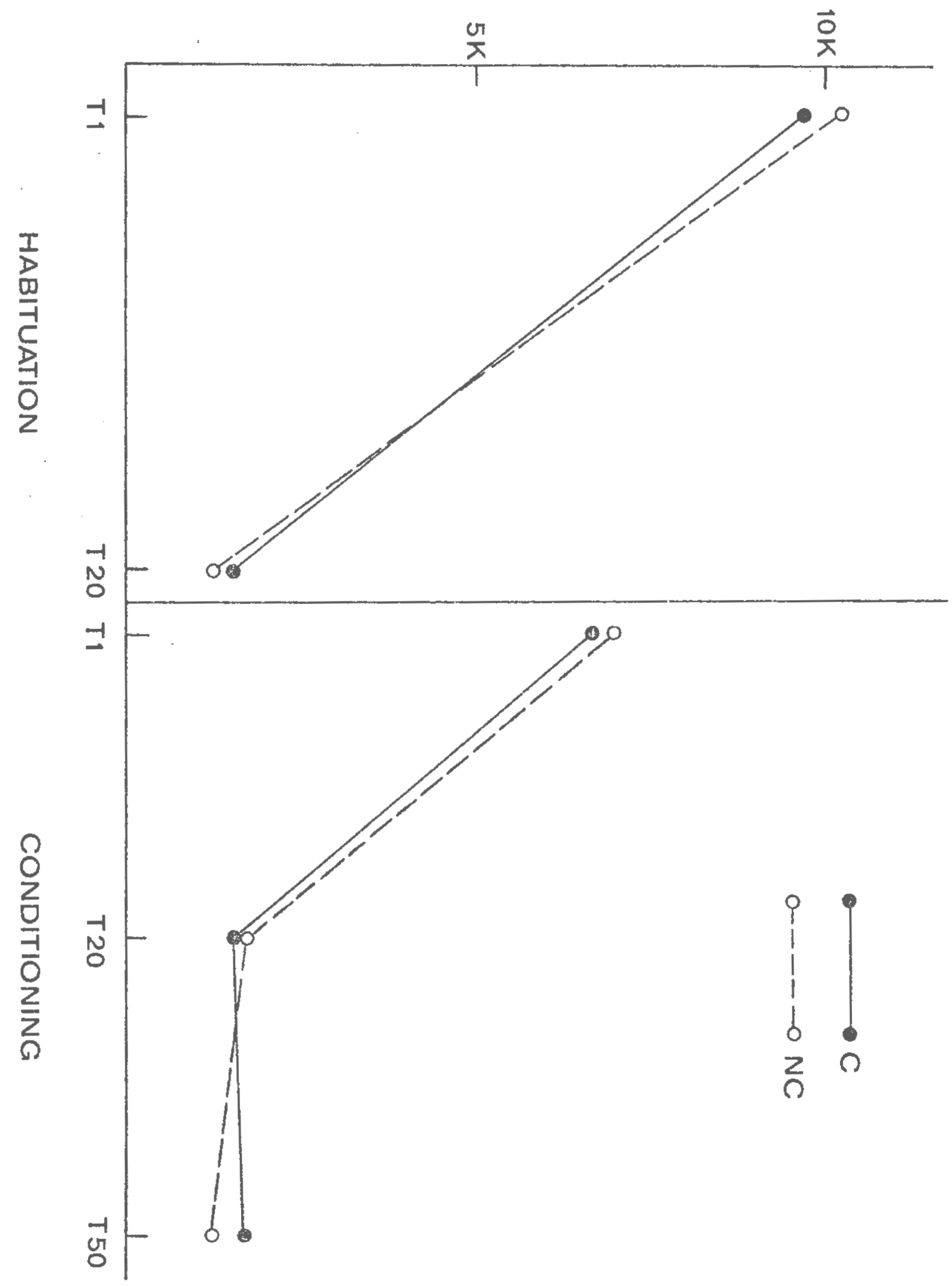




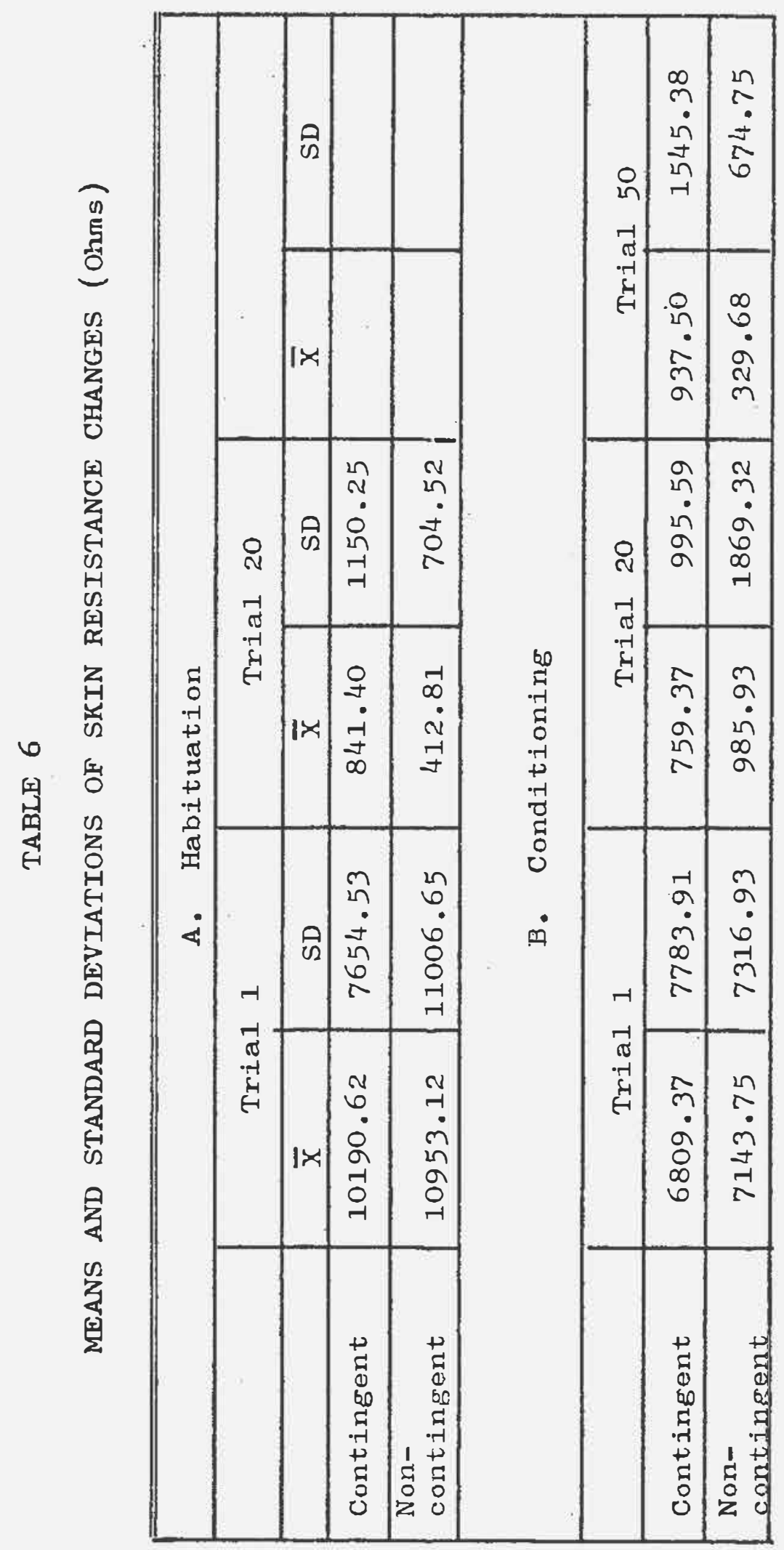


conditioning. Electrodermal conditioning had previously been demonstrated by others using positive reinforcement procedures (Shnidman, 1970). Kimme1, et al. (1967) had used a procedure similar to the one used in this study, with normals and retardates. In their study the SRR was first elicited with visual stimuli and then reinforced with candy. The control subjects were reinforced for not responding. Kimme1, et a1.'s normal subjects behaved differently from the retardates in that the normals reinforced for not responding performed better than those reinforced for responding, and better than retardates run under similar conditions. However, neither the acquisition rates nor the overall difference between retarded groups reinforced for the SRR and those reinforced for withholding SRRs were significantly different, a result perhaps paralleling the present findings.

Other reasons can be offered as to why no SRR conditioning was obtained. For example, the mental ages of the subjects could have been too diverse. As others (e.g. Grings, Lockhart and Dameron, 1962) have shown, SRR reactivity is somewhat related to intelligence; perhaps if the subjects in the present study had been restricted to either the profound and severe ranges or the moderate and mild ranges, a more reliable picture of instrumental SRR conditioning may have emerged. Another reason for lack of conditioning may have been that only a single, one hour conditioning session was given. This may not have been enough time to instrumentally 
condition the SRR in retardates. Finally, although not exhausting the list of possibilities, the average number of reinforcements per subject in this study was 32.5. Considering the difficulties involved in conditioning the autonomic nervous system in the first place (Shearn, 1973), this number of reinforced trials may not have been adequate for obtaining instrumental SRR conditioning in institutionalized retardates.

To summarize the SRR data, no conditioned SRR was measured. Habituation and dishabituation of the SRR occurred much as predicted for normals by Sokolov's OR Theory. Since no rormal subjects were run, it is not possible to know whether the SRR pattern demonstrated by the retardates in this study was different from that which would be displayed by normals exposed to the same parameters.

The original prediction regarding discrimination learning was that group CWN would make more correct responses than the other groups. The data in Figure 2 (p. 38) were interesting since the group hypothesized to do well (CWN) appear to have a more steeply accelerated learning curve and appear to reach assymptote earlier than the remaining groups. Unfortunately, the main effect of conditioning was not statistically significant.

Another possibility was that even if the experimental subjects did not make more correct responses than the control subjects by the end of the learning period, that group 
CWN subjects would learn the task earlier than the other subjects. This is suggested by the backward learning curves presented by Zeaman and House (1963). These showed that the learning curves generated by normals and retardates had similar acceleration but that compared to normals, the retardates did not accelerate until later in the learning trial sequence. Thus, facilitated learning could have been evidenced in the form of reaching assymptote earlier or having a more steeply accelerated learning curve. Neither of these possibilities were seen in the data of the present study. One way of explaining Group CWN's performance is that conditioning of the oR did occur but that it was not reflected in the SRR measure used to operationally define the OR in this study. If such an OR did occur, however, it was not reflected in the effect of conditioning on the learning of the discrimination task. It is also conceivable that the SRR occurred during the learning of the discrimination problem and thus affected Group CWN's learning. The above possibilities are suggested by a significant three way Trials $\mathrm{X}$ Conditioning $\mathrm{X}$ White Noise interaction $(F=13.5, \mathrm{~d} f=$ 4/240, p $<.01$ ) during learning but cannot be supported by the measures taken in this study.

It could also be that correctness was not affected by the experimental procedure since being correct may more properly be a function of cue selection or selectivity rather than a function of general alertness or preparation 
(Posner and Boies, 1971). Selectivity refers to the subjects attending to specific cues which may or may not be related to the solution of a discrimination problem. Preparation refers to a general alertness which exposes the subject to both relevant and irrelevant cues equally and occurs either prior to cue selection or simultaneously with it. The OR is also thought to be at least partly selective in that a person can habituate to one stimulus of a particular frequency but will become disinhibited by a stimulus of a slightly different frequency. However, Sokolov (1963) presented the results of several studies in which a more general effect of the oR was demonstrated. The function of the $O R$ is to increase the sensitivity of the sensory analyzers and provide an optimum condition for perception of stimuli regardless of sensory modality stimulated. For example, Sokolov (1958) found that when a sound stimulus produced an OR, photic driving produced by a light flicker and previously habituated, returned more markedly. Thus, if the effect of the oR is to alert the subject, and if once the alerting occurs, there is little difference in the acquisition of a simple discrimination response between retardates and normals as demonstrated by Zeaman and House (1963), perhaps a difference in correctness on the learning task in the present study should not have occurred. The alerting function of the OR is clearly seen in the present study in the results due to white noise presentation during discrimination learning. 
A major finding in the present study was that white noise facilitated response latency. Thus the groups having the white noise stimulus immediately preceding the onset of the discrimination problem made their responses, irrespective of being correct or incorrect, faster than subjects not having the white noise. All groups also performed faster at the end of the discrimination learning phase than at the beginning, and increasing control of the instrumental button pressing response was indicated because all groups made more correct responses over trials.

The present data did not show that the white noise stimulus presented in conjunction with the discrimination task facilitated correctness of responding. Others, (e.g. Zeaman and House, 1963) have shown, however, that the properties of stimuli to be discriminated affect not only the correctness of responding but how much attention is paid to these stimuli. Thus Zeaman and House (1963) found that retardates performed better on a discrimination task when three-dimensional stimuli were used than when two-dimensional stimuli were part of the task. Learning of the task took place earlier in the learning trial sequence with threedimensional stimuli but the final acquisition rates for both the three and two-dimensional stimuli were highly similar. It appeared that three-dimensional stimuli were easier to discriminate from each other. Further, Baumeister, Urquart, Beedle and Smith (1964) found that the reaction time of re- 
tardates could be facilitated if the stimulus to be reacted to was made more intense. Other operations have also been performed on the task stimuli to make them more discriminable, such as, for example, contiguously pairing the to-bepositive discriminative cue with reward prior to discrimination learning to facilitate such learning (Eimas and Shepp, 1964). These findings indicate that by making relevant stimuli more discriminable, more easily selected, the retardate's learning could be facilitated. The white noise used in the present study was not directly relevant to the solution of the task. Further, an oR to the white noise stimulus should render both the correct and incorrect stimuli "equally" discriminable since the functional effect of the on would be to make the visual analyzer more sensitive (Sokolov, 1963) without affecting the properties of the stimulus.

It is possible that the subjects who responded more quickly were also attending to the task to a greater degree than the slow responders. Presentation of a signal stimulus resulted in shorter latencies indicating that these subjects were ready to respond on the task earlier (were more alert) on a given trial than subjects not having the white noise.

The finding that presenting a white noise stimulus facilitated the latency of responding on a visual (motor) task is analogous to the findings of reaction time studies of intersensory facilitation (e.g. Nickerson, 1970 ). 
Nickerson (1970) presented a reaction time task to two groups of normal subjects, ore of which had a tone precede a light (subjects react to light by pressing a telegraph key) and a second which did not have the tone precede the light. The interstimulus interval of the tone-light was varied such that the tone could precede the light, come on simultaneously, or the light could precede the tone. Nickerson found that for the tone-light combination group, reaction time was significantly faster than for the light only group when the tone occurred simultaneously with the light or when the tone preceded the light for up to $400 \mathrm{msec}$. It was also found that if the light preceded the tone by 25 msec., that the tonelight subjects responded significantly faster than light only subjects. Others have also found that an auditory stimulus can facilitate reaction time to a visual stimulus depending upon the interstimulus interval (e.G. Bertelson, 1967), and that such facilitation may even be obtained when the visual reaction time stimulus precedes the auditory warning stimulus (Morre11, 1967; Bernstein, 1970). There is no evidence in the literature for intersensory facilitation of reaction time in retardates. In fact, Baumeister, Hawkins and Koenigsknecht (1965) found that various warning stimuli had no effect on the reaction time of retardates. They presented visual, auditory, or a combination of these warning signals at three different interstimulus intervals prior to a visual reaction time signal, 
a red light. The desired response was the word "red" to the red lights coming on. Neither the visual nor the auditory nor their combination facilitated reaction time. When a visual warning signal was used in conjunction with a visual reaction signal, Hawkins, Baumeister and Holland (1965) obtained slower reaction times compared to a nowarning signal condition in retardates.

Future Research

Several changes in approach and objectives were suggested by the outcome of the foregoing research. The present findings indicate a need for a systematic study of bot!l initial reactivity as well as habituation to both auditory and visual stimulation. Information relating stimulus intensity and duration, to autonomic activity would help to elaborate the concept of the orienting response in the retardate. The related question as to the possibility of gaining instrumental control over autonomic responses in the retarded remains to be demonstrated. A 1ess ambitious study of just instrumental SRR conditioning in retardates may provide basic data which could then be utilized in a study such as the present one.

With regard to paying attention during learning, the finding that white noise presentation facilitated response latency suggests the need for parametric variation of the interval between white noise onset and discrimination task onset. It would be important to demonstrate an inter- 
sensory facilitation effect in the retarded as this could conceivably lead to more practical ways of maintaining the retardate's attention in the classroom. It may also be instructive to have the subjects learn to a criterion, and plot the resulting data in the form of backward learning curves. This would aid in making inferences as to how and when retardates pay attention during discrimination learning. 


\section{CONCLUSIONS}

The original hypothesis in the present study that learning a discrimination task would be facilitated by a white noise previously contiguous with a reinforced orienting response was not supported, probably due to the lack of an SRR conditioning effect.

The evidence obtained in the present study appears relevant to a more general aspect of attention, that is, alertness of the subjects producerl by the orienting response. Evidence presented above indicates that the retardates' ability to attend to a task and select specific cues are probably different processes underlying attention. The present study found that white noise facilitated response latency on a two choice color discrimination task, but correctness of responding on the task was not affected by the white noise.

The facilitated response latency seems likely due to the alerting effect of the orienting response elicited by the white noise stimulus. The subjects having the white noise appeared to attend to the discrimination problem sooner than the no-white-noise subjects. 
APPENDICES 
APPENDIX A

Matching Data

MENTAL AGE (MA) AND ZERO TRIALS (ZT)

\begin{tabular}{|c|c|c|c|c|c|c|c|c|}
\hline \multirow[t]{2}{*}{ Group } & \multicolumn{2}{|c|}{ CWN } & \multicolumn{2}{|c|}{ CNWN } & \multicolumn{2}{|c|}{ NCWN } & \multicolumn{2}{|c|}{ NCNWN } \\
\hline & MA & $\mathrm{ZT}$ & $\mathrm{MA}$ & $\mathrm{ZT}$ & MA & $\mathrm{ZT}$ & MA & $\mathrm{ZT}$ \\
\hline & 68 & 3 & 59 & 3 & 57 & 1 & 54 & 6 \\
\hline & 80 & 7 & 92 & 8 & 46 & 3 & 82 & 5 \\
\hline & 102 & 6 & 59 & 1 & 34 & 1 & 48 & 2 \\
\hline & 50 & 8 & 35 & 8 & 108 & 8 & 62 & 10 \\
\hline . & 79 & 6 & 40 & 2 & 57 & 6 & 51 & 7 \\
\hline & 32 & 2 & 69 & 5 & 61 & 5 & 108 & 4 \\
\hline & 73 & 15 & 57 & 5 & 69 & 13 & 32 & 0 \\
\hline & 68 & 10 & 108 & 12 & 78 & 10 & 74 & 10 \\
\hline & 36 & 8 & 52 & 8 & 68 & 6 & 86 & 12 \\
\hline & 62 & 15 & 57 & 12 & 68 & 16 & 62 & 14 \\
\hline & 110 & 10 & 48 & 10 & 54 & 13 & 88 & 10 \\
\hline & 70 & 6 & 92 & 7 & 116 & 8 & 72 & 8 \\
\hline & 51 & 5 & 53 & 5 & 51 & 5 & 108 & 5 \\
\hline & 32 & 5 & 47 & 4 & 62 & 2 & 54 & 3 \\
\hline & 92 & 4 & 110 & 3 & 56 & 2 & 43 & 3 \\
\hline & 56 & 1 & 62 & 3 & 60 & $\mathrm{O}$ & 40 & 2 \\
\hline
\end{tabular}




\section{APPENDIX B}

Table 1

Summary of Analysis of Variance

\begin{tabular}{|l|r|r|r|r|}
\hline \multicolumn{6}{|c|}{ SRR Conditioning Data } \\
\hline Source of Variables & \multicolumn{1}{|c|}{ Ss } & $\mathrm{df}$ & $\mathrm{MS}$ & F Ratio \\
\hline Conditioning (C) & 3.61 & 1 & 3.61 & 0.23 \\
Error (between Ss) & 972.74 & 62 & 15.68 & \\
Trials (T) & 166.89 & 4 & 41.72 & $17.67^{* *}$ \\
T X C & 4.98 & 4 & 1.24 & 0.52 \\
Error (within Ss) & 585.33 & 248 & 2.36 & \\
\hline
\end{tabular}

${ }^{* *} \mathrm{p}<.001$ 


\section{APPENDIX C \\ Table 1}

Summary of Analysis of Variance

\begin{tabular}{|c|c|c|c|c|}
\hline \multicolumn{5}{|c|}{ Number of Correct Responses } \\
\hline Source of Variation & SS & df & MS & F Ratio \\
\hline Conditioning (c) & $34 \cdot 5$ & 1 & $34 \cdot 5$ & 0.81 \\
\hline White Noise (W) & 17.6 & 1 & $17 \cdot 6$ & 0.42 \\
\hline $\mathrm{C} \mathrm{X} W$ & 48.8 & 1 & 48.8 & 1.18 \\
\hline Error (between Ss) & 2474.1 & 60 & $41 \cdot 2$ & \\
\hline Trials (T) & $163 \cdot 3$ & 4 & 40.8 & $18.50 * *$ \\
\hline$T \times C$ & 10.2 & 4 & $2 \cdot 5$ & 1.13 \\
\hline $\mathrm{T} X \mathrm{X}$ & $4 \cdot 5$ & 4 & $1 \cdot 1$ & 0.50 \\
\hline$T \times C X \quad W$ & 119.2 & 4 & 29.8 & $13 \cdot 50 * *$ \\
\hline Error (within ss) & 530.0 & 240 & 2.2 & \\
\hline
\end{tabular}

$* * \mathrm{p}<.001$ 


\section{APPENDIX D}

Table 1

Summary of Analysis of Variance

\begin{tabular}{|l|r|r|r|c|}
\hline \multicolumn{5}{|c|}{ Response Latency Data } \\
\hline Source of Variation & SS & df & MS & F Ratio \\
\hline Conditioning (C) & 8.02 & 1 & 8.02 & 0.01 \\
White Noise (W) & 3304.22 & 1 & 3304.22 & $5.71^{*}$ \\
C X W & 213.44 & 1 & 213.44 & 0.36 \\
Error (between Ss) & 34665.46 & 60 & 577.75 & \\
Trials (T) & 998.46 & 3 & 332.82 & $7.60^{*}$ \\
T X C X & 202.84 & 3 & 67.61 & 1.54 \\
T X W & 153.10 & 3 & 51.03 & 1.16 \\
T X C X W & 147.05 & 3 & 49.01 & 1.12 \\
Error (within Ss) & 7874.80 & 180 & 43.74 & \\
\hline
\end{tabular}

* $\quad \mathrm{p}<.025$

** $\quad \mathrm{p}<.001$ 


\section{REFERENCES}

Baumeister, A. A., \& Kellas, G. Distribution of reaction times of retardates and normals. American Journal of Menta1 Deficiency, 1968, 72, 715-718.

Baumeister, A. A., Hawkins, W. F., and Koenigsknecht, R. Effects of variation in complexity of the warning signal upon reaction Time. American Journal of Mental Deficiency, $1965,69,860-864$.

Baumeister, A. A., Urquhart, D., Beedle, R., and Smith, R. Reaction times of normals and retardates under different stimulus intensity changes. American Journal of Mental Deficiency, $1964,69,126-130$.

Bertelson, P. Central intermittency twenty years later. Quarterly Journal of Experimental Psychology, 1967, $18,153-163$.

Boneau, C. A. The effects of violations of assumption underlying the t test. Psychological Bulletin, 1960, 57, $49-65$

Boyle, R., Dykman, R., and Ackerman, P. Relationship of resting autonomic activity, motor impulsivity, and EEG tracings in children. Archives of General Psychiatry, $1965, \underline{2}, 314-323$

Clausen, $J_{.}$, and Karrer, R. OR frequency of occurrence and relationship to other autonomic variables. American Journal of Mental Deficiency, 1968, 73, 455-464. 
Eimas, P. D., and Shepp, B. E. Retardate discrimination learning following differential conditioning of the choice point stimuli. Child Development, 1964, 35, $685-693$.

Ellis, N. R. The stimulus trace and behavioral inadequacy. In N. R. Ellis (Ed.): Handbook of mental deficiency. New York: McGraw-Hill Book Company, 1963. Fenz, W. D., and McCabe, M. W. Habituation of the GSR to tones in retarded children and nonretarded subjects. American. Journal of Mental Deficiency, 1971, 15, 470473.

Furedy, J. J., and Gagnon, Y. Sensitivities of and relationships between blood volume change, pulse volume change, and GSR. Proceedings of the 76th Annual Convention of the American Psychological Association; 1968 , 2. $257-258$

Grings, W. W. Anticipatory and preparatory electrodermal behavior in paired stimulation situations. Psychophysiology, 1969, 5, 597-611.

Grings, W., Lockhart, R., and Dameron, L, Conditioning autonomic responses of mentally subnormal individuals. Psychological Monographs, 1962, 76, \#558.

Hawkins, W. F., Baumeister, A. A., and Holland, J. M. Reaction time in retardates following variation in warning signal intensity and preparatory interval. American Journal of Menta1 Deficiency, 1965, 20, 135-138. 
Heal, L. W., and Johnson, J. T. Jr. Inhibition deficits in retardates learning and attention. International Review of Research in Mental Retardation, 1970, 4, 107-150. Horowitz, F. D. Learning, developmental research, and individual differences. In L. P. Lipsitt, and H. W. Reese (Eds.): Advances in Child Development and Behavior, $1969,4,107-150$.

House, B. J., and Zeaman, D. A comparison of discrimination learning in normal and mentally defective children. Child Development, 1958, 29, 411-416. Jeffrey, W. E. The orienting response and attention in cognitive behavior. Psychological Review, 1968, 75, $323-334$

Johnson, L. C. Some attributes of spontaneous autonomic activity. Journal of Comparative and Physiological Psychology, 1963, 56, 415-422.

Johnson, J. T. Intelligence, inhibition, and the orienting reflex. IMRID Papers and Reports, 1968, V, Number 20. Karrer, R. ANS functions and behavior: a review of experimental studies with mental defectives. International Review of Research in Mental Retardation, 1966, 2, $57-83$

Karrer, R., and Clausen, J. A comparison of mentally deficient and normal individuals upon four dimensions of autonomic activity. Journal of Mental Deficiency Research, $1964, \underline{8}, 149-163$. 
Kaxrer, R., and Clausen, $J$. Autonomic levels and variables during reduced stimulation in mental defectives and normal children. American Journal of Mental Deficiency, $1967, \quad 71,990-993$.

Kaye, H. Infant sucking behavior and its modification: In: L. P. Lipsitt, and C. C. Spiker (Eds.): Advances in Child Development and Behavior, 1967, 2, 1-52.

Kimme1, H. D., Pendergrass, V. E., and Kimme1, E. B. Modifying childrens orienting responses instrumentally. Conditional Retlex, 1967, 2, 227-233.

Kleinman, K. M. , and Stern, J. A. Task complexity, electrodermal activity, and reaction time. Psychophysiology, $1968,1,51-60$.

Lacey, J. I., and Lacey, B. C. The relationship of resting autonomic activity to motor impulsivity. Proceedings of the Association of Nervous and Mental Disorder, 1958, 36, $109-144$.

Lindquist, E. F. Design and analysis of experiments in psychology and education, pages 78-90, Boston, HoughtonMifflin Company, 1953.

Lobb, H., Moffitt, A., and Gamlin, P. Frustration and adaptation in relation to discrimination learning ability of mentally defective children. American Journal of Mental Deficiency, 1966, 11, 256-265.

Luria, A. R. The mentally retarded child: essays based on a study of the higher nervous functioning of child oligophrenics. Oxford, Pergamon Press, 1963. 
Lynn, R. Attention, arousal, and the orienting response. In: International Series of Monographs in Experimental Psychology; H. J. Eysenck (Ed.): New York: Pergamon Press, 1966.

McCal1, R. B., and Kagan, J. Attention in the infant: effects of complexity, contour, perimeter, and familiarity. Science, 1969, 172, 354-356.

Morrell, L. K. Intersensory facilitation of reaction time. Psychonomic Science, 1967, 8, 77-78. Nickerson, R. S. The effect of preceding and following auditory stimuli on response times to visual stimuli. lcta Psychologica, Attention and Performance III, A. F. Sanders (Ed.): 1970, 33, 5-20.

Obrist, P., Hallman, S., and Wood, D. Autonomic levels and lability, and performance time on a perceptual task and a sensorimotor task. Perceptual and Motor Ski11s, 1964 , 18, $753-762$

Pilgrim, D. L.,Miller, F. D., and Cobb, H. V. GSR strength and habituation in normal and nonorganic mentally retarded children. American Journal of Mental Deficiency, $1969,74,27-31$

Polikanina, R., and Sergeeva, L. On the development of extinctive inhibition in children in early ontogenesis. Zhurnal Vysshei Nervnoi Deyatelni, 1967, 17, 228-239. Posner, M. I., and Boies, S. J. Components of attention. Psychological Review, 1971, 78, 391-408. 
Raskin, B., Kotsess, M., and Bever, B. B. Autonomic indicators of the OR and DR. Journal of Experimental Psychology, $1969,80,423-433$.

Razran, G. Mind in evolution: an east-west synthesis of learned behavior and cognition. Boston: HoughtonMifflin, 1971.

Ross, L. E., and Ross, S. M. Classical conditioning and intellectual deficit. In: D. K. Routh (Ed.): The experimental psychology of mental retardation, Chicago: Aldine Pub1ishing Company, 1973.

Shearn, D. W. Operant analysis in psychophysiology. In: Greenfie1d, N. S., and Stermback, R. A. (Eds.): Handbook of psychophysiology. New York: Holt, Rinehart, and Winston, Inc., 1973.

Shnidman, S. R. Instrumental conditioning of orienting responses using positive reinforcement. Journal of Experimental Psychology, 1970, 83, 491-494.

Sokolov, Ye. N., 1958, reviewed in Sokolov, Ye. N. (1963). Sokolov, Ye. N. Perception and the conditioned reflex.

New York: Macmillan, 1963.

Stevenson, H. W., and Zigler, E. Probability learning in children. Journal of Experimental Psychology, 1958, 56, $185-192$.

Tizard, B. Habituation of EEG and skin potential changes in normal and severely subnormal children. American Journal of Menta1 Deficiency, 1968, 73, 34-40. 
Vogel, W. The relationship of age and intelligence to autonomic functioning. Journal of Comparative and Physio1ogical Psychology, 1961, 54, 133-138.

Zeaman, D. One programmatic approach to retardation. In: D. K. Routh (Ed.): The experimental psychology of mental retardation. Chicago: Aldine Publishing Company, 1973. Zeaman, D., and House, B. J. The role of attention in retardate discrimination learning. In: N. R. Ellis (Ed.): Handbook of Mental Deficiency. New York: McGraw-Hil1, 1963.

Zigler, E. The retarded child as a whole person. In: D. K. Routh (Ed.): The experimental psychology of mental retardation. Chicago: Aldine Publishing Company, 1973. 